\title{
Influence of personality and fatalistic belief on taxi driver behaviour
}

\author{
Bright Mahembe and Olorunjuwon Michael Samuel
}

\begin{abstract}
The religious perception among individuals in sub-Saharan Africa that the 'Big Five' personality dimensions and fatalism are predictors of drivers' behaviours and road accidents has received little scientific investigations. This paucity of research in the roles of psychological factors such as personality and fatalistic beliefs in shaping positive driver behaviour and attitudes has thus provided motivation for the conduct of this quantitative study. We collected data from 203 conveniently sampled taxi drivers in Gauteng province of South Africa by means of a structured questionnaire. Our analysis, using Structural Equation Modelling, found significant positive relationships between agreeableness and positive driver behaviour, conscientiousness and positive driver behaviour, fatalism and extraversion, as well as fatalism and positive driver behaviour. The results highlighted the dimensions of being methodical, organised, and risk aversive on the road, on the one hand, and being social, cooperative, and good-natured, on the other hand. Findings of the study further indicated that fatalistic beliefs are prevalent and indeed characteristic of individuals who are sociable, gregarious, and assertive. These individuals tend to uphold their religious and spiritual beliefs in the linkages between road accidents and destiny. Insights provided by this study could assist the Department of Transport and related Road Safety Authorities in designing road safety campaigns that addresses the erroneous beliefs by drivers that road accidents are pre-destined, and not as a result of individual's driving behaviour.
\end{abstract}

Documented evidence (e.g., Ameratunga, Hijar, \& Norton, 2006) suggested that approximately one million people were killed globally due to road accidents on a yearly basis. In South Asia, approximately 250,000 people die annually as a result of road accidents with countries like Pakistan accounting for about 40,000 of these road accidents (Kayani, King, \& Fleiter, 2011). The sub-Saharan Africa has also experienced a rapid rise in the number of road accidents. Peltzer (2008) provided an approximation of the following statistics of fatal road accidents in some sub-Sahara African countries in the year 2011: Zimbabwe $(34,000)$, South Africa (10,845), Zambia (22,750), and Botswana (18,001). Most of the road accidents have been largely attributed to human factors such as age, level of education, and gender (Iversen \& Rundmo, 2004; Nordfjærn, Jørgensen, \& Rundmo, 2010; Peltzer, 2008; Yagil, 1998), while others could be attributed to drivers' attitudes and behaviours on the roads (Iversen, 2004). Although innovation has significantly improved mechanical and safety standards in automobile manufacturing, and with improvements in road infrastructure by various governments, little has been done to understand the psychological factors 
underpinning driver behaviour and attitudes. Scientific understanding of this psychological attribute will assist in reducing accidents on our roads (Kwadjo, Knizek, \& Rundmo, 2013; Iversen, 2004; Nordfjærn et al., 2010).

Previous studies conducted in other continents (e.g., Europe) demonstrated a link between differences in culture and driving behaviours (Association Amicale des Ingenieurs Ancien El\&es de I'Ecole cited in Lajunen, Carry, Summala, \& Hartley, 1998). The authors suggested a considerable influence of culture on the way drivers assess their driving skills and perception of safety on the road, thus accounting for differences in accident statistics across countries. Research by Berry, Poortinga, Segall, and Dasen (1992) showed that social behaviour, cognitive processes and attitudes are influenced by cultural background of drivers. Cross-cultural literature derive support from the study by Sivak et al. (cited in Factor, Mahalel, \& Yair, 2007) who firmly established the influence of culture on drivers' selfevaluation, perception, and risk-taking propensity among drivers in the United States of America, Germany, Spain, and Brazil. Similar to Sivak and colleagues' finding, Shinar, Dewar, Summala, and Zakowska (2003) argued that cultural norms have considerable influence on the extent of expected aggressiveness and norms and these changes both between countries and within a country. As a preventive measure, the authors reported that drivers in South Africa commonly engage in spiritual activities such as using protective charms, consulting traditional healers or prophets, and rituals in order to avoid future accidents. Such spiritual and superstitious beliefs among drivers are consistent with such practices in other African countries like Ivory Coast and Nigeria (Dixey, 1999; Kouabenan, 1998). It is within the cultural and spiritual context described above that this article is conceptualised. The article is thus located within the framework of the cultural theory of risk (Douglas \& Wildavsky, 1982) which asserts that structures of social organisation endow individuals with perceptions that reinforce those structures in competition against alternative ones. Cultural settings and values, such as fatalism, therefore have an important role in shaping risk perception of the individuals (Şimşekoğlu et al., 2013).

Personality traits such as risk propensity, sensation-seeking, and the 'Big Five' personality traits (conscientiousness, openness to experience, emotional stability, extraversion, and agreeableness) have variously been found to exert influence on drivers' attitudes and behaviours while driving (Henning et al., 2008, p. 338). The authors described risk propensity as the extent to which individuals are inclined to take risks, seek adventure, and engage in risky behaviours (e.g., hang-gliding, gambling), while sensation-seeking refers to the propensity to seek adventure and avoid boredom (Rosenbloom \& Wolf, 2002). Risk propensity and sensation-seeking are subtypes of the extraversion personality trait. Henning et al. (2008) found significant relationships between agreeableness, conscientiousness, prevention regulatory focus, and fatalism and all the six safety attitudes examined in this article. The authors further reported significant relationships between agreeableness, prevention focus, and fatalism and safety attitudes when controlling for the other individual differences. The role of personality traits is further reinforced in a study conducted by Kouabenan (2002) on risk perception and causal explanations of road accidents which showed that participants were inclined to overestimate the threat represented by the 
risk of a road accident. Participants in the study tended to make more external causal attributions that defended their role in traffic safety and accident prevention. The study concluded that both experienced and less experienced drivers demonstrated a higher level of risk-taking than other participants who also made more external and fatalistic causal attributions.

Fatalism is similar to an external locus of control for safety, in which individuals lack feelings of control over safety and do not believe they are direct contributors to and causes of accidents (Forcier, Walters, Brasher, \& Jones, 2001; Jones \& Wuebker, 1993). Fatalistic thinking might lead to negligent attitude towards hazards (Rundmo \& Hale, 2003) and does not differ with accident experience (Williamson, Feyer, Cairns, \& Biancotti, 1997). Studies in West African countries such as Ivory Coast and Nigeria indicated that fatalistic beliefs influenced the perception of predisposed individuals who hold such beliefs towards taking more risks and neglect safety measures (Kouabenan, 1998). In Nigeria, for example, some people drive under the influence and belief in the ability and efficacy of certain 'charms' or talisman that could prevent their involvement in road accidents (Sarma, 2007).

Neuroticism is a fundamental personality trait that is essentially characterised by anxiety, fear, moodiness, worry, envy, frustration, jealousy, and loneliness (Thompson, 2008). Neurotics are known to experience such feelings as anxiety, anger, envy, guilt, and depressed mood (Matthews \& Deary, 1998). They respond more poorly to stressors, are more likely to interpret ordinary situations as threatening, and minor frustrations as hopelessly difficult. Costa and McCrae (1992) reported that anxiety was significantly related to negative affect. The driver's level of negative effect might influence his or her interpretation of the traffic environment and driving behaviour.

The primary objective of this study was to conduct an analysis of the relationships between personality, fatalistic beliefs, and driver behaviour and attitude. The secondary objective was to validate a theoretical model explicating the structural relationships between these variables in the South African context. In order to achieve these objectives, we hypothesised that (1) conscientiousness positively affects driver behaviour, (2) openness to experience is negatively related with positive driver behaviour, (3) extraversion positively affects positive driver behaviour, and agreeableness positively affects positive driver behaviour. We further hypothesised that fatalism positively affects positive driver behaviour, (6) neuroticism negatively affects positive driver behaviour, (7) conscientiousness negatively affects fatalism, and (8) openness to experience positively affects fatalism. Finally, the following hypotheses were formulated to further assist in the achievement of our stated objectives: (9) extraversion negatively affects fatalism, (10) agreeableness is positively related to fatalism, and (11) neuroticism positively affects fatalism.

After an in-depth investigation of the literature, a conceptual model was derived. Figure 1 illustrates the conceptual model that depicts the specific hypothesised causal linkages between personality, fatalism, and positive driver behaviour. 


\section{Method}

\section{Participants}

The study participants comprised 203 taxi drivers drawn from two large taxi hubs in the Johannesburg Central Business District. The taxi hubs are considered to be the largest in the Gauteng province hosting the highest concentration of intra- and inter-province minibus operators. All participants $(n=203)$ were male $(100 \%)$, with $42 \%$ (i.e., 86$)$ falling within the age category of between 21 and 30 years, while $58 \%$ (i.e., 117) comprised drivers between the age category of between 31 and 65 years. The ethnic distribution of the sample was 100\% Black (Africans). Approximately $53.7 \%$ of the sample obtained matriculation qualification, 40.4\% had primary school education, while 5.9\% had no formal education.

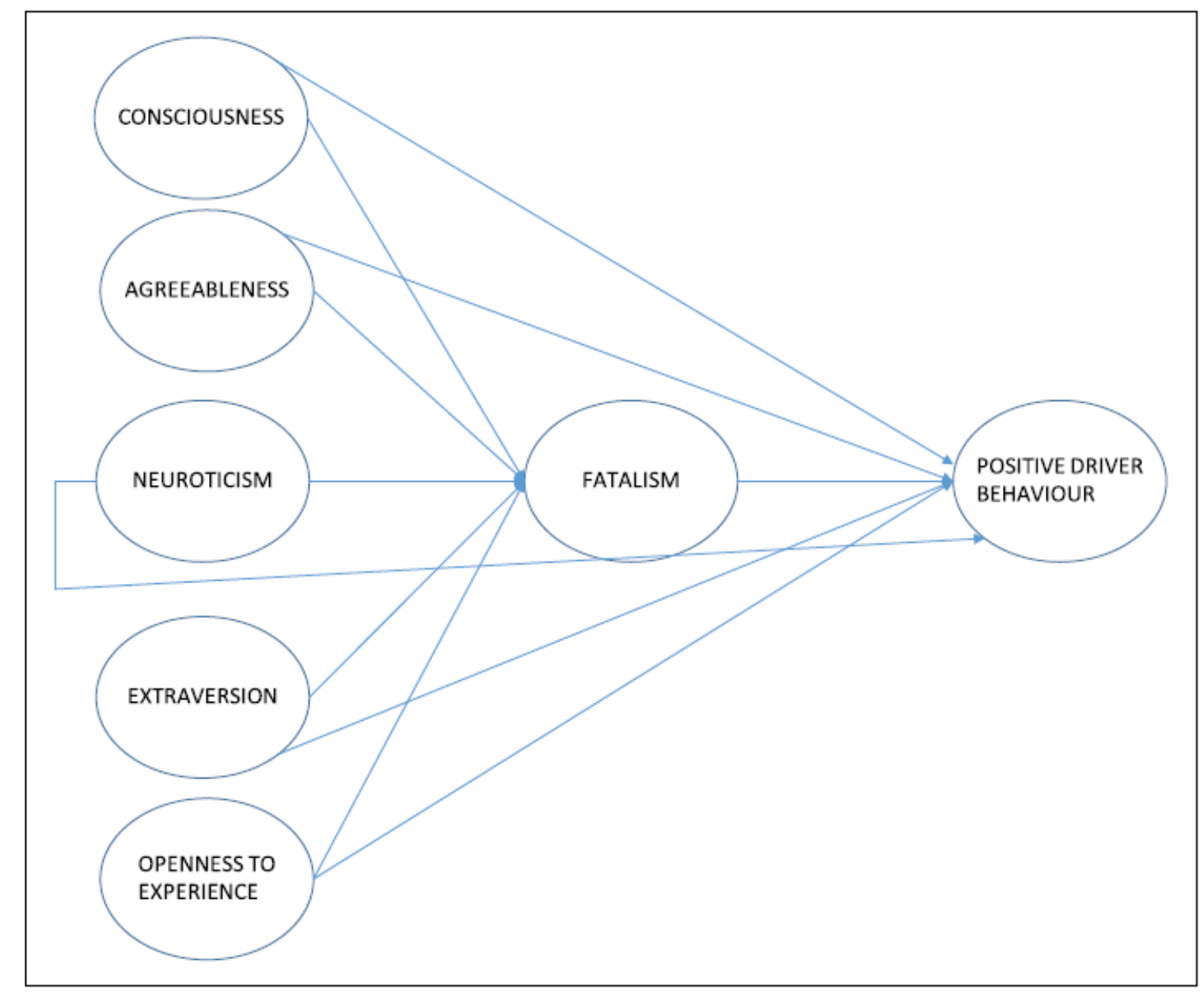

Figure I. The theoretical model.

\section{Instruments}

The Big Five personality factors were assessed with an International Personality Item Pool (IPIP) measure. The IPIP is a measure of the Big Five personality dimensions taken from the International Personality Item Pool (Goldberg, 1999; Goldberg et al., 2006). The instrument contains a total of 50 items (both positively and negatively keyed) that are presented in brief statements. Each personality dimension includes 10 items. The negatively worded items were reverse coded. All responses were made on a 5 -point scale ranging from $1=$ very inaccurate to 
$5=$ very accurate. The instruments demonstrated strong internal consistency with Cronbach's alpha values for the IPIP-BFD subscales as follows: Extraversion $(\alpha=.86)$, Agreeableness $(\alpha=.81)$, Neuroticism $(\alpha=.85)$, Conscientiousness $(\alpha=.77)$, and Openness to experience $(\alpha=.80)$ (Gow, Whiteman, Pattie, \& Deary, 2005; Jensen-Campbell et al., 2002).

Positive driver behaviour. An adapted version of the positive driver behaviour scale developed by Özkan and Lajunen (2005) was used to measure drivers' positive driver behaviour. The scale reported a Cronbach's alpha of .84 and was used on a sample of Turkish drivers in Ankara (Özkan \& Lajunen, 2005). Example of the items include 'I adjust my speed to help the driver trying to overtake' and 'I let pedestrians cross even if it is my right to pass'. The eight items used were measured by a 6-point Likert scale ranging from 'never' to 'always'.

Fatalism. An adapted version of the fatalism scale developed by Şimşekoğlu et al. (2013) was used to measure fatalism. The scale showed a reliability coefficients of $\alpha=.81$ on a Turkey sample and $\alpha=.87$ on an Iranian sample (Şimşekoğlu et al., 2013). Example of the items include 'Precautions are unnecessary, since there is no way to avoid destiny' and 'I take signs from gods or spirits seriously'. The items were measured by a 7-point Likert scale ranging from 'strongly disagree' to 'strongly agree'.

\section{Procedure}

Participants were courteously approached by the data collector who administered the questionnaires at the two taxi hubs. He explained the purpose of the study to each participant in isiZulu and Sesotho languages (mostly spoken by participants) and assisted them in completing the questionnaire items by interpreting and providing guidance. A total of 400 questionnaires were administered, while 230 were returned ( $58 \%$ return rate). The nonprobability sampling strategy using convenience and purposive sampling techniques (Bryman \& Bell, 2011) was employed in sampling the participants. Only 203 of the returned questionnaires were usable.

The problem of missing values was addressed through multiple imputations (Jöreskog \& Sörbom, 2006). The advantage of the multiple imputation procedures available in LISREL 8.80 is that estimates of missing values are derived for all cases in the initial sample (i.e., no cases with missing values are deleted) and the data set is available for subsequent item and dimensionality analyses, and the formation of item parcels (Du Toit \& Du Toit, 2001; Mels, 2003).

\section{Ethical considerations}

Ethical clearance was obtained from University of the Witwatersrand Ethics Committee. The respondents were duly informed of the purpose of the study through a cover letter which provided the rationale for the study (Malhotra, 2010). The cover letter also specified the participants' right to confidentiality, voluntary participation, and informed consent and was interpreted to participants by the data collector. 


\section{Data analysis}

The model was tested using structural equation modelling. Item and dimensional analyses were conducted to determine the reliability and uni-dimensionality of the instruments as well as identify poor items. Due to the small sample size, two parcels were formed for each of the latent variables used in the study by taking the mean of the even-numbered and the mean of the uneven-numbered items of the subscales to operationalise the seven latent variables. The big five personality traits were treated as exogenous latent variables for the study.

\section{Results}

\section{Uni-dimensionality}

Both item and exploratory factor analyses were performed on the items of the scales used in the study. Based on the SPSS output on the item analysis, items d18, d19, and d20 of the Openness to experience subscale were identified as poor items with an item total correlation below 0.3 (Pallant, 2010), and the deletion of the items increased the Cronbach's alpha coefficient from $\alpha=.553$ to $\alpha=.655$. The items were therefore excluded from further analyses. Generally, most of the Cronbach's alpha coefficients with the exception of the Openness to experience subscale were above the .70 threshold (Nunnally \& Bernstein, 1994; Pallant, 2010) (see Table 1).

Table I. Descriptive statistics and inter-correlations of the scale scores $(N=203)$.

\begin{tabular}{llclllllll}
\hline Subscales & $M$ & SD & $\mathrm{I}$ & 2 & 3 & 4 & 5 & 6 & 7 \\
\hline I.CONSC & 40.65 & 7.36 & .90 & & & & & & \\
2. OPEN & 24.65 & 4.94 & $.16^{*}$ & .66 & & & & \\
3. EXTRA & 38.20 & 9.79 & $-.17^{*}$ & .13 & .93 & & & \\
4. NEURO & 34.30 & 11.8 & -.05 & .14 & .04 & .97 & & \\
5. AGREE & 36.50 & 8.45 & $.28^{* *}$ & .06 & $.21^{* *}$ & -.03 & .90 & & \\
6. FATAL & 21.79 & 6.94 & .12 & .13 & $.15^{*}$ & .04 & .07 & .79 & \\
7. DRIVER & 32.91 & 7.38 & $.50^{* *}$ & .13 & .03 & .06 & $.29^{* * *}$ & $.35^{* *}$ & .84 \\
\hline
\end{tabular}

SD: standard deviation; CONSC: conscientiousness; OPEN: openness to experience; EXTRA: extraversion; NEURO: neuroticism; AGREE: agreeableness; FATAL: fatalistic beliefs; DRIVER: positive driver behaviour. $N=203$; coefficient alphas for the scales are presented diagonally and are indicated in bold. ${ }^{*} p<.05$ (two-tailed); ${ }^{* * k} p<.01$ (two-tailed).

The scale means, standard deviations, and correlations are also included in Table 1. Exploratory factor analyses were subsequently performed on the subscales of measures used; uni-dimensionality was confirmed on all the subscales with the exception of the personality subscale items which appeared to cluster along the positive versus negatively worded item factors. In this case, the higher order factor was used since the items represent one factor.

\section{Goodness-of-fit: The measurement models}

In terms of the goodness-of-fit (GFI) indices for the measurement model, the root mean square error of approximation (RMSEA) value of .058 indicates that the overall measurement model shows reasonable fit to the data as values below .05 represent good 
model fit and values between .05 and .08 indicate reasonable fit while those above .08 depict poor model fit (Diamantopoulos \& Siguaw, 2000). The $p$-value of .245 for Test of Close Fit indicates that the model shows close fit to the data (see Table 2). The standardised root mean square residual (RMR) value of .044 falls within the .05 cut-off indicative of good model fit. The overall measurement model GFI value reached the .90 level required to indicate good fit (Diamantopoulos \& Siguaw, 2000). The normed fit index (NFI), non-normed fit index (NNFI), comparative fit index (CFI), incremental fit index (IFI) and relative fit index (RFI) indices are greater than .90, which represents good fit (Diamantopoulos \& Siguaw, 2000). These relative indices therefore demonstrate a positive picture of model fit.

\section{Measurement model factor loadings}

The completely standardised factor loading for the items contained in the overall measurement model exceeded the $>.50$ level (Hair, Black, Babin, \& Anderson, 2010). This implies that the item parcels reflect the dimension they were designed to represent.

\section{GFI indices for the structural model}

The GFI indices for the structural model indicate reasonable model fit. The RMSEA value of .056 and $p$-value of .312 show good and close model fit to the data (see Table 2). The standardised RMR value of .045 is within the .05 cut-off level. The structural model GFI reached the .90 level required to indicate good fit (Diamantopoulos \& Siguaw, 2000). The NFI, NNFI, CFI, IFI, and RFI indices are greater than .90, which represents good fit (Diamantopoulos \& Siguaw, 2000).

Table 2. Goodness-of-fit indices obtained for the measurement and structural model.

\begin{tabular}{lllllllll}
\hline Model & RMSEA & $P_{\text {close fit }}$ & SRMR & GFI & AGFI & NNFI & NFI & CFI \\
\hline Measurement & .058 & .245 & .044 & .92 & .84 & .95 & .92 & .97 \\
Structural & .056 & .312 & .045 & .91 & .83 & .95 & .92 & .97 \\
\hline
\end{tabular}

RMSEA: root mean square error of approximation; Pclose fit: $p$-value for test of close fit $(\mathrm{H} 0: \mathrm{RMSEA}<.05)$; SRMR: standardised root mean residual; GFI: goodness-of-fit; AGFI: adjusted goodness-of-fit index; NNFI: non-normed fit index; CFI: comparative fit index. 
Table 3. The gamma matrix indicating the relationships between exogenous (independent) and endogenous (dependent) variables.

\begin{tabular}{lcccccc}
\hline & CONSC & OPENNES & EXTRA & AGREE & NEUROT & FATAL \\
\hline FATAL & .10 & .006 & .241 & .019 & .054 & \\
& $(.083)$ & $(.070)$ & $(.085)$ & $(.075)$ & $(.047)$ & \\
& 1.18 & 0.081 & $2.83 *$ & 0.26 & 1.16 & \\
DRIVER & .395 & .002 & .032 & .262 & -.021 & .269 \\
& $(.092)$ & $(.062)$ & $(.082)$ & $(.078)$ & $(.062)$ & $(.081)$ \\
& $4.29 *$ & 0.03 & 0.39 & $3.33 *$ & -0.344 & $3.30 *$ \\
\hline
\end{tabular}

CONSC: Conscientiousness; OPEN: openness to experience; EXTRA: extraversion; NEURO: neuroticism; AGREE: agreeableness; FATAL: fatalistic beliefs; DRIVER: positive driver behaviour.

Completely standardised path coefficients; standard error estimates (in brackets); parameter estimates in bold.

*Indicates significant parameter estimates $t \geqslant 1.96 ;{ }^{*} p<.05$ (two-tailed); ${ }^{* *} p<.01$ (two-tailed).

\section{Other key findings}

A positive relationship was found between conscientiousness and positive driver behaviour $(t=4.29, p<.05)$, while the SEM path between affective openness to experience and positive driver behaviour was non-significant $(t=.03, p>.05)$. Similarly, the path between extraversion and positive driver behaviour was not significant $(t=.39, p>.05)$. We found a positive relationship between agreeableness and positive driver behaviour $(t=3.33, p$ $<.05)$. Furthermore, a positive relationship was found between fatalism and positive driver behaviour $(t=3.30, p<.05)$. The path between neuroticism and positive driver behaviour was found to be non-significant, while the path between conscientiousness and fatalism was also not significant $(t=1.18, p>.05)$. The path between openness to experience and fatalism was not significant $(t=.08, p>.05)$. We further found a positive relationship between extraversion and fatalism $(t=2.83, p<.05)$, while the path between agreeableness and fatalism was found to be non-significant. Finally, the path between neuroticism and fatalism showed a non-significant relationship.

\section{Discussion}

The purpose of the present study was to investigate the influence of personality and fatalism on positive driver behaviour. The primary goal of the study was to conduct an analysis of the relationships between personality, fatalistic beliefs, and driver behaviour and attitude. The secondary goal was to validate a theoretical model explicating the structural relationships between these variables in the South African context.

With regard to the fit of the model, the GFI indices indicated that both the measurement and the structural models produced reasonable fit (see Table 2). The results indicated that the items measured the dimensions (latent variables) as postulated, as well as supported the theoretical model underlying the postulated relationships between the latent personality, fatalism, and positive driver behaviour variables. Previous research has indicated that personality variables are direct contributors to involvement in risky driving behaviour (Dahlen, Martin, Ragan, \& Kuhlman, 2005; Schwebel, Severson, Ball, \& Rizzo, 2006; Ulleberg \& Rundmo, 2003). 
Our finding of a positive relationship between conscientiousness and positive driver behaviour is consistent with studies such as Arthur and Doverspike (2001) and Arthur and Graziano (1996), which generally agree that higher levels of conscientiousness are associated with reduced risky driving behaviours. This suggests that drivers could avert accidents on the road through careful and vigilant behaviour. A conscientious driver could, for example, adjust his or her speed in order to allow a speeding driver overtake. Furthermore, we found a non-significant result in the SEM path between affective openness to experience and positive driver behaviour contrary to our stated hypothesis (2). The six dimensions of openness include active imagination (fantasy), aesthetic sensitivity, attentiveness to inner feelings, preference for variety, and intellectual curiosity (Costa \& McCrae, 1992). A combination of these dimensions could inform a driver's positive behaviour on the road, and this outcome could therefore explain the results of our finding which is supported by McCrae and John (1992) who found a significant positive relationship between openness to experience and positive driver behaviour. However, other studies reported inconsistent findings. Iversen and Rundmo (2002) found that sensationseeking is one of the best predictor of self-reported driving violations while Burns and Wilde (1995) found links between sensation-seeking and risky driving on the job among a sample of almost 80 professional taxi drivers that were surveyed.

On the relationship between extraversion and positive driver behaviour, we could not find support for hypothesis (3) as stated since the path between extraversion and positive driver behaviour was found to be non-significant. Documented evidence suggests that extraversion is positively associated with traffic accidents (Lajunen, 2001), road errors (Verwey \& Zaidel, 2000), and violations of traffic rules. Literature has however generally found extraversion to be positively associated with considerate behaviour (Thørrisen, 2013). This is due to the fact that individuals possessing a high level of extraversion are predisposed to have both positive affect and cognitions. Such individuals are optimistic about the future, less susceptible to distraction, and less affected by competition than introverts (Eysenck, 1981).

A positive association found between agreeableness and positive driver behaviour in the present study could be linked to the assumption that individuals who are high in agreeableness are gentle, cooperative, forgiving, understanding, and good natured (Waldman, Atwater, \& Davidson, 2004); it is expected that these individuals are likely to be courteous and display positive driver behaviour on the road. In an inverse postulation, Anitei and Dumitrache (2013) failed to find statistically significant correlation between agreeableness and aggressive driving behaviour, thus providing consistency with our research finding.

A further analysis of the data showed a positive relationship between fatalism and positive driver behaviour $(t=3.30, p<.05)$. This research outcome is consistent with similar findings by Henning et al. (2008) who found a significant relationship between agreeableness, conscientiousness, prevention regulatory focus, and fatalism and all the six 
safety attitudes that were examined in the instant study. However, contrary studies postulated a tendency by fatalists to bother themselves less about events or outcomes that are beyond their personal control (such as road accidents), resulting in a lower risk perception (Rippl, 2002). Such fatalistic beliefs tend to explain events by uncontrollable and random factors, such as fate or bad luck, which are unchangeable (Şimşekoğlu et al., 2013). Thus, fatalists are passively inclined towards traffic safety, which in turn may lead to less willingness to take precautions or obey traffic rules (Kouabenan, 1998; Peltzer \& Renner, 2003). Hence, fatalism is a potentially important variable that might influence both traffic risk perception and driver behaviours especially in countries with a high degree of religious conservatism (e.g., South Africa).

With regard to neuroticism and driver behaviour, the present study found a non-significant path between neuroticism and positive driver behaviour. Garrity and Demick (2001) reported a significant relationship between the mood state tension-anxiety, which is strongly related to neuroticism and negative driving behaviour. Deffenbacher, Deffenbacher, Lynch, and Richards (2003) found that high-anger drivers reported more frequent and intense anger and more aggression and risky driving behaviour in their daily driving. They also reported greater anger in frequently occurring situations, more frequent close calls, and higher speed of driving since they consider such situations as threatening.

We equally found a non-significant path between conscientiousness and fatalism, in the same vein as the path between openness to experience and fatalism. Fatalism has been likened to an external locus of control for safety, in which individuals lack feelings of control over safety and do not believe they directly contribute to or cause accidents (Forcier et al., 2001; Jones \& Wuebker, 1993). Williamson et al. (1997) found that fatalism did not change with experience, or differ for those with accident experience, leading them to conclude fatalism may be an enduring individual difference rather than an attitude or perception regarding safety climate. Kouabenan (1998) demonstrated that fatalistic individuals take bigger risks because they possess limited knowledge of risks and accidents, leading them to under-estimate the probability of their occurrence.

Further results of the study indicated a positive relationship between extraversion and fatalism. This finding is supported by Thørrisen (2013) who found a positive association between extraversion and considerate behaviour, thus suggesting that individuals who exhibit this behaviour are likely to conform to societal beliefs and norms. The path between agreeableness and fatalism was not significant, suggesting that drivers who are low in agreeableness are often sceptical about other road users' motives, resulting in suspicion and unfriendliness, and more likely to compete than cooperate on the road (Graziano \& Eisenberg, 1997).

Finally, we found limited support for the hypothesised positive relationship between neuroticism and fatalism. This outcome is congruent with those of Henning et al. (2008) who found neuroticism to be negatively related to safety discipline. 
The following poses possible limitations to the present study: data gathering instrument was written in English language which could create difficulty in accurate translation by the participants. The use of non-probability sampling, coupled with localisation of the research setting to the Gauteng province, could make generalisation of the research findings difficult. Future studies should therefore consider a wider coverage of both private and commercial drivers across the country. Furthermore, cross-sectional survey could increase the chances of same-source or common method biases (Podsakoff \& MacKenzie, 1994), which could be reduced by using longitudinal research design. Podsakoff and MacKenzie argued that longitudinal research studies could, among others, permit better assessment of the causal priority of personality, fatalism, and positive driver behaviour and further enable examination of the longer term effects of personality, fatalism, and positive driver behaviour. Future research could consider the possibility of expanding the theoretical model by formally incorporating additional latent variables like cultural experiences and emotional intelligence. More important, a greater psychometric refining of the measuring instruments used in this study should be considered by future researchers.

\section{Conclusion}

Engaging in positive driver behaviour would, to a great extent, assist in reducing the amount of road accidents in South Africa. The results of this research have provided evidence to the extent that the conscientiousness and agreeableness personality facets play a role in the promotion of positive road behaviour. The study further demonstrated that fatalistic beliefs also influence drivers' behaviour, and these beliefs are also influenced by drivers' extraversion personality facet.

\section{Funding}

The author(s) received no financial support for the research, authorship, and/or publication of this article. 


\section{References}

Ameratunga, S., Hijar, M., \& Norton, R. (2006). Road-traffic injuries: Confronting disparities to address a global-health problem. The Lancet, 367, 1533-1540.

Anitei, M., \& Dumitrache, A. (2013). Correlative study between personality traits and aggression at young driver-a pilot study. International Journal of Traffic and Transportation Psychology, 1(2), 5-20.

Arthur, W., Jr., \& Doverspike, D. (2001). Predicting motor vehicle crash involvement from a personality measure and a driving knowledge test. Journal of Prevention \& Intervention in the Community, 22(1), 35-42.

Arthur, W., Jr., \& Graziano, W. G. (1996). The five-factor model, conscientiousness, and driving accident involvement. Journal of Personality, 64, 593-618.

Berry, J. W., Poortinga, Y. H., Segall, M. H., \& Dasen, P. R. (1992). Cross-cultural psychology: Research and applications. Cambridge, UK: Cambridge University Press.

Bryman, A., \& Bell, E. (2011). Business research methods (3rd ed.). Oxford, UK: Oxford University Press. Burns, P. C., \& Wilde, G. J. S. (1995). Risk taking in male taxi drivers; relationships among personality, observational data and driver records. Personality and Individual Differences, 18, 267-278.

Costa, P. T., Jr., \& McCrae, R. R. (1992). Revised NEO Personality Inventory (NEO-PI-R) and NEO Five-Factor Inventory (NEO-FFI) professional manual. Odessa, FL: Psychological Assessment Resources.

Dahlen, E. R., Martin, R. C., Ragan, K., \& Kuhlman, M. K. (2005). Driving anger, sensation seeking, impulsiveness, and boredom proneness in the prediction of unsafe driving. Accident Analysis \& Prevention, 37, 341-348.

Deffenbacher, J. L., Deffenbacher, D. M., Lynch, R. K., \& Richards, T. L. (2003). Anger, aggression, and risky behavior: A comparison of high and low anger drivers. Behaviour Research and Therapy, 41, 701-718. doi:10.1016/Sooo5-7967(02)ooo463

Diamantopoulos, A., \& Siguaw, J. A. (2000). Introducing LISREL. London, England: SAGWE.

Dixey, R. A. (1999). Fatalism, accident causation and prevention: Issues for health promotion from an exploratory study in a Yoruba town, Nigeria. Health Educational Research, 14, 197-208.

Douglas, M., \& Wildavsky, A. (1982). Risk and culture: An essay on selection of technological and environ- mental dangers. Berkeley: California University Press.

Du Toit, M., \& Du Toit, S. H. C. (2001). Interactive LISREL: User's guide. Lincolnwood, IL: Scientific Software International.

Eysenck, H. J. (1981). General features of the model. In H. J. Eysenck (Ed.), A model for personality (pp. 1-37). Berlin, Germany: Springer.

Factor, R., Mahalel, D., \& Yair, G. (2007). The social accident: A theoretical model and a research agenda for studying the influence of social and cultural characteristics on motor vehicle accidents. Accident Analysis \& Prevention, 39, 914-921.

Forcier, B. H., Walters, A. E., Brasher, E. E., \& Jones, J. W. (2001). Creating a safer work environment through psychological assessment: A review of a measure of safety 
consciousness. In A. Stuhlmacher \& D. Cellar (Eds.), Workplace safety: Individual differences in behavior (pp. 53-65). Chicago, IL: Hayworth Press.

Garrity, R. D., \& Demick, J. (2001). Relations among personality traits, mood states, and driving behaviors. Journal of Adult Development, 8, 109-118.

Goldberg, L. R. (1999). A broad-bandwidth, public-domain, personality inventory measuring the lower-level facets of several Five-Factor models. In I. Mervielde, I. J. Deary, F. de Fruyt, \& F. Ostendorf (Eds.), Personality psychology in Europe (Vol. 7, pp. 7-28). Tilburg, The Netherlands: Tilburg University Press.

Goldberg, L. R., Johnson, J. A., Eber, H. W., Hogan, R., Ashton, M. C., Cloninger, C. R., \& Gough, H. C. (2006). The international personality item pool and the future of public-domain personality measures. Journal of Research in Personality, 40, 84-96.

Gow, A. J., Whiteman, M. C., Pattie, A., \& Deary, I. J. (2005). Goldberg's 'IPIP' Big-Five factor markers: Internal consistency and concurrent validation in Scotland. Personality and Individual Differences, 39, 317-329.

Graziano, W. G., \& Eisenberg, N. (1997). Agreeableness: A dimension of personality. In R. Hogan, S. Briggs, \& J. Johnson (Eds.), Handbook of personality psychology (pp. 795-824). San Diego, CA: Academic Press.

Hair, J. F., Black, W. C., Babin, B. J., \& Anderson, R. E. (2010). Multivariate data analysis: A global perspective (7th ed.). Upper Saddle River, NJ: Pearson. doi:10.1016/j.jmva.2009.12.014

Henning, J. B., Stufft, C. J., Payne, S. C., Bergman, M. E., Mannan, M. S., \& Keren, N. (2008). The influence of individual differences on organizational safety attitudes. Safety Science, 47, 337-345.

Iversen, H. H. (2004a). Risk behaviour in traffic: A study investigating relationships between attitudes, personality, stress and behaviour. Trondheim, Norway: Department of Psychology, NTNU.

Iversen, H. H. (2004b). Risk-taking attitudes and risky driving behaviour. Transportation Research Part F: Traffic Psychology and Behaviour, 7, 135-150.

Iversen, H. H., \& Rundmo, T. (2002). Personality, risky driving and accident involvement among Norwegian drivers. Personality and Individual Differences, 33, 1251-1263.

Iversen, H. H., \& Rundmo, T. (2004). Attitudes towards traffic safety, driving behaviour and accident involvement among the Norwegian public. Ergonomics, 47, 555-572.

Jensen-Campbell, L. A., Rosselli, M., Workman, K. A., Santisi, M., Rios, J. D., \& Bojan, D. (2002). Agreeableness, conscientiousness, and effortful control processes. Journal of Research in Personality, 36, 476-489.

Jones, J. W., \& Wuebker, L. J. (1993). Safety locus of control and employees' accidents. Journal of Business and Psychology, 7, 449-457.

Jöreskog, K. G., \& Sörbom, D. (2006). LISREL 8.80 for Windows [Computer Software]. Lincolnwood, IL: Scientific Software International.

Kayani, A., King, M. J., \& Fleiter, J. J. (2011). Fatalism and road safety in developing countries, with a focus on Pakistan. Journal of the Australasian College of Road Safety, 22(2), 41-47. 
Kouabenan, D. R. (1998). Beliefs and the perception of risks and accidents. Risk Analysis, 18, 243-252. Kouabenan, D. R. (2002). Occupation, driving experience, and risk and accident perception. Journal of Risk Research, 5, 49-68.

Kwadjo, E. T., Knizek, B. L., \& Rundmo, T. (2013). Attitudinal and motivational aspects of aberrant driving in a West African country. Tidsskrift for Norsk Psykologforening, $50,451-461$.

Lajunen, T. (2001). Personality and accident liability: Are extraversion, neuroticism and psychoticism related to traffic and occupational fatalities? Personality and Individual Differences, 31, 1365-1373.

Lajunen, T., Carry, A., Summala, H., \& Hartley, L. (1998). Cross-cultural differences in drivers' self-assessments of their perceptual-motor and safety skills: Australians and Finns. Person Individual Differences, 24, 539-550.

Malhotra, N. K. (2010). Marketing research: An applied orientation. Englewood Cliffs, NJ: Prentice Hall. Matthews, G., \& Deary, I. J. (1998). Personality traits. Cambridge, UK: Cambridge University Press.

McCrae, R. R., \& John, O. P. (1992). An introduction to the Five-Factor Model and its applications. Journal of Personality, 6o, 175-215.

Mels, G. (2003). A workshop on structural equation modelling with LISREL 8.54 for Windows. University of Port Elizabeth, Port Elizabeth, South Africa.

Nordfjærn, T., Jørgensen, S. H., \& Rundmo, T. (2010). An investigation of driver attitudes and behaviour in rural and urban areas in Norway. Safety Science, 48, 348-356.

Nunnally, J. C., \& Bernstein, I. H. (1994). Psychometric theory (3rd ed.). New York, NY: McGraw-Hill. Özkan, T., \& Lajunen, T. (2005). A new addition to DBQ: Positive Driver Behaviours Scale. Transportation Research Part F: Traffic Psychology and Behaviour, 8, 355-368. doi:10.1016/j.trf.2005.04.018

Pallant, J. (2010). SPSS survival manual: A step by step guide to data analysis using SPSS (4th ed.). London, England: McGraw-Hill.

Peltzer, K. (2008). The road 'kill' factor. HSRC Review, 6(4): 31-32.

Peltzer, K., \& Renner, W. (2003). Superstition, risk-taking and risk perception of accidents among South African taxi drivers. Accident Analysis \& Prevention, 35, 619-623.

Podsakoff, P. M., \& MacKenzie, S. B. (1994). An examination of the psychometric properties and nomological validity of some revised and reduced 'substitutes for leadership' scales. Journal of Applied Psychology, 79, 702-713. doi:10.1037/00219010.79.5.702

Rippl, S. (2002). Cultural theory and risk perception: A proposal for a better measurement. Journal of Risk Research, 5, 147-165.

Rosenbloom, T., \& Wolf, Y. (2002). Sensation seeking and detection of risky road signals: A developmental perspective. Accident Analysis \& Prevention, 34, 569-580.

Rundmo, T., \& Hale, A. R. (2003). Manager's attitudes towards safety and accident prevention. Safety Science, 41, 557-574.

Sarma, B. A. (2007). Beliefs and character: Theology and ethics of road safety in Nigeria. Research Bulletin, 48, 13-27. 
Schwebel, D. C., Severson, J., Ball, K. K., \& Rizzo, M. (2006). Individual difference factors in risky driving: The roles of anger/hostility, conscientiousness, and sensationseeking. Accident Analysis and Prevention, 38, 801-810.

Shinar, D., Dewar, R. E., Summala, H., \& Zakowska, L. (2003). Traffic symbol comprehension: A cross-cultural study. Ergonomics, 46, 1549-1565.

Şimşekoğlu, Ö., Nordfjærn, T., Zavareh, M. F., Hezaveh, A. M., Mamdoohi, A. R., \& Rundmo, T. (2013). Risk perceptions, fatalism and driver behaviors in Turkey and Iran. Safety Science, 59, 187-192. Thompson, E. R. (2008). Development and validation of an international English big-five mini-markers. Personality and Individual Differences, 45, 542-548.

Thørrisen, M. M. (2013). Personality and driving behaviour: The role of extraversion and neuroticism in drivers' behaviour toward bicyclists (Unpublished master's thesis). University of Oslo, Norway.

Ulleberg, P., \& Rundmo, T. (2003). Personality, attitudes and risk perception as predictors of risky driving behaviour among young drivers. Safety Science, 41, 427-443.

Verwey, B. W., \& Zaidel, D. M. (2000). Predicting drowsiness accidents from personal attributes, eye blinks an ongoing driving behaviour. Personality and Individual Differences, 28, 123-142.

Waldman, D. A., Atwater, L. E., \& Davidson, R. A. (2004). The role of individualism and the five-factor model in the prediction of performance in a leaderless group discussion. Journal of Personality, 72, 1-28.

Williamson, A. M., Feyer, A. M., Cairns, D., \& Biancotti, D. (1997). The development of a measure of safety climate: The role of safety perceptions and attitudes. Safety Science, $25,15^{-27}$.

Yagil, D. (1998). Gender and age-related differences in attitudes toward traffic laws and traffic violations. Transportation Research Part F: Traffic Psychology and Behaviour, 1, 123-135. doi:10.1016/S1369-8478(98)ooo10-2 